\title{
Serial MRI in HIV Infection With and Without Neurologic Impairment
}

\author{
George H. Dooneief \\ Jacqueline A. Bello \\ George G. Todak \\ Ming X. Tang \\ Karen S. Marder \\ Yaakov Stern \\ Richard P. Mayeux
}

\begin{abstract}
To assess the relationship of longitudinal brain magnetic resonance imaging (MRI) and infection with human immunodeficiency virus (HIV), a cohort of HIV+ and HIV - gay men and injection drug users (IDU) were evaluated prospectively. Subjects underwent two evaluations including MRI scans, neurologic examinations, neuropsychological assessments and lymphocyte subset determinations one year apart. MRI changes over a one year period
\end{abstract}

George H. Dooneief is affiliated with the HIV Center for Clinical and Behavioral Studies (P50-1-MH43520) at the New York State Psychiatric Institute, Department of Neurology and the Gertrude H. Sergievsky Center; Jacqueline A. Bello is affiliated with the Department of Radiology; George G. Todak is affiliated with the HIV Center for Clinical and Behavioral Studies; Ming X. Tang is affiliated with the Department of Neurology and the Gertrude H. Sergievsky Center; Karen S. Marder is affiliated with the HIV Center for Clinical and Behavioral Studies at the New York State Psychiatric Institute, Department of Neurology and the Gertrude H. Sergievsky Center; Yaakov Stern and Richard P. Mayeux are affiliated with the HIV Center for Clinical and Behavioral Studies at the New York State Psychiatric Institute, Departments of Neurology and Psychiatry and the Gertrude H. Sergievsky Center at Columbia University College of Physicians and Surgeons, New York, NY 10032.

Address correspondence to: Dr. George H. Dooneief, Columbia UniversitySergievsky Center, P \& S Box \#16, 630 W. 168th Street, New York, NY 10032.

Additional support for this study was provided by federal grant \#MH44959.

Journal of Neuro-AIDS, Vol. 1(4) 1996

(c) 1996 by The Haworth Press, Inc. All rights reserved. 
were analyzed with respect to serostatus, risk group, CD4 counts, neurological findings and neuropsychological performance. The frequency of MRI changes was no different in subjects with or without HIV infection and no new opportunistic infections or neoplasms were seen. However, among HIV + subjects with CD 4 count $<200$ at the time of the initial scan, an increase in white matter hyperintensities was significantly more common. Also among HIV+ subjects, atrophy increased in association with declining CD4 count. Finally, subjects who developed significant neurologic deterioration in one year were much more likely to have increased atrophy. These results suggest that while there are morphological brain changes associated with HIV infection, they are most often seen in association with immunologic or neurologic deterioration. [Article copies available for a fee from The Haworth Document Delivery Service: 1-800-342-9678. E-mail address: getinfo@haworth.com]

KEYWORDS. Magnetic resonance imaging (MRI), human immunodeficiency virus (HIV) infection, gay men, injection drug users, prospective, longitudinal, neurologic, neuropsychological

\section{INTRODUCTION}

To assess longitudinal structural changes in the brain associated with human immunodeficiency virus (HIV) infection, we performed serial magnetic resonance imaging (MRI) scans in a cohort of HIV-infected subjects and uninfected controls from similar risk groups. Scan changes were then compared with neurological, neuropsychological and immunological parameters over the same one year period.

\section{SUBJECTS AND METHODS}

Subjects enrolled in a study of the natural history of HIV infection (1) were recruited to participate in a longitudinal MRI study. Solicitation of subjects into this study was approved by the Columbia Presbyterian Medical Center institutional review board and informed consent was obtained from all subjects.

Subject characteristics and the biannual medical, neurological and neuropsychological evaluations performed in the natural history study have been described elsewhere (2). Subjects were considered to have 
HIV-1-associated dementia complex (ADC) or HIV-1-associated minor cognitive/motor disorder (MCMD) if they met the research case definitions (3).

Scans were performed on a 1.5 Tesla system (Philips Medical Systems). The imaging protocol consisted of T-2 weighted axial and coronal scans $(\mathrm{TR}=3500$ and $\mathrm{TE}=80$ ), with a slice thickness of $5 \mathrm{~mm}$ and a $4 \mathrm{~mm}$ gap. Images were acquired on a $512 \times 512$ matrix. Scans were evaluated by a single neuroradiologist (JB) who was aware of each subject's age but was shielded from serostatus and other clinical details. Scan quality was rated as excellent, adequate, inadequate or incomplete and only data from excellent or adequate scans were included in the analysis. Atrophy, small areas of high signal intensity, larger focal lesions and other abnormalities were recorded on a standard form.

Atrophy was subjectively rated as absent, mild, moderate or marked for the subject's age. Small foci of high signal intensity $(>=3 \mathrm{~mm}$ and $<2 \mathrm{~cm}$ ) were rated as absent, single, few ( $<5$ and $<2$ confluent), multiple ( $>=5$ or 2 confluent) or diffuse (many confluent or foci $>=2 \mathrm{~cm}$ ) and their number and locations were recorded. Larger focal lesions indicative of opportunistic infections or neoplasms were recorded. Follow-up scans were rated in an identical fashion by the same neuroradiologist, shielded from the initial radiologic findings. The initial and follow-up scans were then compared side by side to assess scan angle, cortical atrophy (sulcal widening), central atrophy (ventricular enlargement) and overall atrophy (both cortical and central). Scan angle was rated same, similar or disparate. Atrophy was rated as unchanged, increased or decreased to the extent that the similarity of the scan angle allowed.

Analysis of variance and statistical methods for rates and proportions were used to compare characteristics of the various groups $(4,5)$. Logistic regression was used in the calculation of odds ratios. The relationship between changes in CD4 counts and MRI variables was also assessed by multiple analysis of covariance.

\section{RESULTS}

Two hundred thirty-seven subjects were scanned initially and 188 $(79 \%)$ had a second scan approximately one year later. Of the 49 subjects who were not rescanned, 14 died, 20 refused a repeat scan, 7 subjects could not be located, 4 were unable to complete the second scan because of claustrophobia, 2 were not completed because of mechanical problems and 2 were excluded because of abnormalities on their initial scan (presumed progressive multifocal leukoencephalopathy). 
The subjects are described in Table 1 . There were no significant differences in mean age, education, neuropsychological or neurologic measures between the HIV-positive (HIV+) and HIV-negative (HIV - ) subjects at the time of their follow-up scans, but CD4 counts were significantly lower in the HIV+ subjects. In Table 2, data from the time of the initial scans are contrasted for those who underwent follow-up scans and those who did not and with the subset of subjects who died during the follow-up interval. All of the subjects who died were HIV+ and their CD4 counts were significantly lower than those of other subjects.

At follow-up, $6 \mathrm{HIV}+$ subjects met criteria for incident MCMD, but none met criteria for ADC. As would be expected, the MCMD subjects were significantly more impaired on a neurologic disability rating scale modified (2) from the Kurtzke disability status scale for multiple sclerosis (6) than neurologically asymptomatic HIV+ subjects. They were also more impaired

TABLE 1. Study subjects.

\begin{tabular}{|c|c|c|c|c|c|}
\hline & ALL & $\begin{array}{c}\text { HIV+ gay } \\
\text { men }\end{array}$ & $\begin{array}{c}\text { HIV - gay } \\
\text { men }\end{array}$ & HIV+ IDU & HIV - IDU \\
\hline $\mathrm{N}$ & 178 & 57 & 34 & 48 & 39 \\
\hline Age & $40.7(7.9)$ & $40.0(7.7)$ & $40.7(8.3)$ & $41.5(7.3)$ & $40.7(8.7)$ \\
\hline Educ (yr) & $14.0(3.4)$ & $15.9(2.3)$ & $16.8(2.3)$ & $11.8(2.7)$ & $11.3(2.5)$ \\
\hline CD4 count & $574(354)$ & $368(244)$ & $879(313)$ & $394(229)$ & $863(276)$ \\
\hline
\end{tabular}

IDU = injection drug user

Values in parentheses represent standard deviations about the accompanying group means

TABLE 2. Comparison of subjects with and without follow-up scans and the subset of subjects without follow-up scans who died in the follow-up interval.

\begin{tabular}{|c|c|c|c|}
\hline & Follow-up & No follow-up & Died \\
\hline $\mathrm{N}$ & 188 & 49 & 11 \\
\hline Age & $39.7(7.9)$ & $40.0(7.7)$ & $38.8(8.1)$ \\
\hline Education & $13.9(3.4)$ & $14.1(2.9)$ & $14.2(2.4)$ \\
\hline$\%$ HIV+ & $60 \%$ & $60 \%$ & $100 \%^{*}$ \\
\hline CD4 count & $596(369)$ & $549(440)$ & $144(104)^{*}$ \\
\hline incomplete data & & & 3 \\
\hline
\end{tabular}

- $p<0.001$

Values in parentheses represent standard deviations about the accompanying group means 
with respect to neuropsychological summary measures and had lower mean CD4 counts, though these differences were not statistically significant.

Follow-up scan results are displayed in Table 3 . Ten subjects had scans inadequate for interpretation due to motion artifact. No new opportunistic infections or neoplasms were seen. Atrophy and WMH were seen with the same frequency as in the initial scans (7), and there were no statistically significant associations between changes in atrophy or WMH and HIV serostatus or risk group (Table 4).

Changes in WMH were not associated with MCMD, but increases in atrophy (overall, central and cortical) among the HIV+ subjects were associated with MCMD $\left(\chi^{2}=15.2, p<.001 ; \chi^{2}=8.2, p=.004 ; \chi^{2}=7.2, p=\right.$ .007 , respectively). To address the impact of the degree of immune deficiency on MRI changes, HIV+ subjects were divided into 2 categories based on their CD4 counts at the time of the initial scan: those with CD4 counts $>=200 / \mathrm{mm}^{3}$ and those with CD4 counts $<200 / \mathrm{mm}^{3}$. Chi-square analyses revealed no association between changes in atrophy and initial CD4 count. Those with an initial CD4 count $<200 / \mathrm{mm}^{3}$ were more likely to have an increase in WMH (odds ratio $=3.2 ; 95 \%$-confidence interval [1.0-10.4]; $p=0.04)$. Separate analyses of covariance were performed comparing CD4 counts at the time of the follow-up MRI scan among those with or without changes in atrophy or WMH [controlling for initial CD4

TABLE 3. Follow-up MRI scan results.

\begin{tabular}{|c|c|c|c|c|}
\hline & HIV+ gay men & HIV-gay men & HIV+ IDU & HIV - IDU \\
\hline $\mathrm{N}$ & 57 & 34 & 48 & 39 \\
\hline Atrophy-none & $5(9 \%)$ & 0 & $2(4 \%)$ & $1(3 \%)$ \\
\hline mild & $45(79 \%)$ & $30(88 \%)$ & $45(94 \%)$ & $31(79 \%)$ \\
\hline moderate & $7(12 \%)$ & $3(9 \%)$ & $1(2 \%)$ & $7(18 \%)$ \\
\hline marked & 0 & $1(3 \%)$ & 0 & 0 \\
\hline WMH-none & $48(84 \%)$ & $27(79 \%)$ & $35(73 \%)$ & $30(77 \%)$ \\
\hline single & $5(9 \%)$ & $3(9 \%)$ & $4(8 \%)$ & $2(5 \%)$ \\
\hline few & $4(7 \%)$ & $4(12 \%)$ & $6(13 \%)$ & $1(3 \%)$ \\
\hline multiple & 0 & 0 & $3(6 \%)$ & $4(10 \%)$ \\
\hline diffuse & 0 & 0 & 0 & $2(5 \%)$ \\
\hline
\end{tabular}

IDU = injection drug user

WMH = white matter hyperintensity

Ten scans were exluded from analysis owing to incompleteness or motion artifact 
TABLE 4. MRI changes.

\begin{tabular}{|c|c|c|c|c|}
\hline & HIV+ gay men & HIV - gay men & HIV+ IDU & HIV - IDU \\
\hline N & 57 & 34 & 48 & 37 \\
\hline $\begin{array}{c}\text { Atrophy- } \\
\text { increased }\end{array}$ & $16(28 \%)$ & $16(47 \%)$ & $19(40 \%)$ & $11(30 \%)$ \\
\hline unchanged & $33(58 \%)$ & $10(29 \%)$ & $21(44 \%)$ & $20(54 \%)$ \\
\hline decreased & $8(14 \%)$ & $8(24 \%)$ & $8(17 \%)$ & $6(16 \%)$ \\
\hline WMH-increased & $8(14 \%)$ & $4(12 \%)$ & $6(13 \%)$ & $4(11 \%)$ \\
\hline unchanged & $44(77 \%)$ & $26(76 \%)$ & $37(77 \%)$ & $31(84 \%)$ \\
\hline decreased & $5(9 \%)$ & $4(12 \%)$ & $5(10 \%)$ & $2(5 \%)$ \\
\hline \hline $\begin{array}{c}\text { Central atrophy- } \\
\text { increased }\end{array}$ & $7(12 \%)$ & $5(15 \%)$ & $6(13 \%)$ & $4(11 \%)$ \\
\hline unchanged & $45(79 \%)$ & $25(74 \%)$ & $38(79 \%)$ & $27(73 \%)$ \\
\hline decreased & $5(9 \%)$ & $4(12 \%)$ & $4(8 \%)$ & $6(16 \%)$ \\
\hline $\begin{array}{c}\text { Cortical atrophy- } \\
\text { increased }\end{array}$ & $16(28 \%)$ & $16(47 \%)$ & $19(40 \%)$ & $10(27 \%)$ \\
\hline unchanged & $34(60 \%)$ & $10(29 \%)$ & $21(44 \%)$ & $20(54 \%)$ \\
\hline decreased & $7(12 \%)$ & $8(24 \%)$ & $8(17 \%)$ & $7(19 \%)$ \\
\hline
\end{tabular}

IDU = injection drug user

WMH = white matter hyperintensity

count, interval between scans (11-13 months for most subjects) and interval between CD4 counts and MRI scans]. A significant relationship was noted only between increasing central atrophy and decreasing CD4 count $(\mathrm{F}=4.76, \mathrm{p}=0.032)$.

\section{DISCUSSION}

The current investigation demonstrates increasing atrophy with neurologic deterioration only in the HIV+ subjects and increasing central atrophy associated with declining CD4 count, but a low incidence of opportunistic infections or malignancies in the brain over one year's time. Severity of immune deficiency at the time of their initial scan was associated with new WMH in HIV+ individuals. Only in those cases at the extremes (MCMD or CD4 < 200) was a significant relationship between neurologic or immunologic changes and MRI changes found. 
This study has several limitations. The imaging protocol did not include Proton-weighted images: such images are more sensitive for small intraparenchymal hyperintensities, but the use of $\mathrm{T} 2$-weighted images in two planes (axial and coronal) reduces this possible source of inaccuracy. Subjective ratings of the degree of atrophy, while internally consistent, are difficult to quantify or generalize. Conversely, subjectively judging the presence or absence of change in interval scans is probably more reliable, though likewise difficult to quantify or generalize.

Global measures of neurological and neuropsychological impairment were used to reduce the chance of type I error that the multiple comparisons with individual test scores or signs would have produced. The use of these measures may have inadvertently obscured subtle relationships between neurologic or neuropsychologic findings and MRI changes, but was non-differential with respect to HIV serostatus. The time frame (one year) may be too brief to visualize significant changes. Lastly, while the subjects with and without follow-up scans were comparable in the aggregate, the association of MRI changes with low CD4 count suggests that the subset of subjects who died during the follow-up interval may have been at greater risk to develop MRI changes. This, in turn, suggests that the results of the current study may be an underestimate of the frequency of such changes. As a consequence, the findings of the current study are probably conservative, but may reflect the average clinical experience.

Other longitudinal studies have demonstrated MRI changes in HIV infection. Serial MRI scans performed as part of the Multicenter AIDS Cohort Study revealed that ventricular enlargement was associated with degree of immunosuppression even in neurologically normal subjects: progressive bicaudate region atrophy was associated with CD4 decline and was most pronounced in individuals developing $\operatorname{ADC}(8,9)$. A longitudinal study of brain MRI in the Middlesex/MRC cohort also demonstrated progression of cerebral atrophy in patients in advanced stages of HIV infection, but noted no deterioration in medically asymptomatic individuals (10). Post et al. reevaluated $74 \mathrm{HIV}+$ subjects with MRI scans after $2-31 / 2$ years. They found that the frequency of abnormal scans was significantly greater in neurologically symptomatic subjects but that the development of new lesions was rare (11). In sum, MRI changes have been of greater severity in individuals with evidence of worsening immunologic status or deteriorating neurologic or neuropsychologic function and there is a suggestion that the relationship has some specificity for deeper central structures.

The current study supports these observations. The study also extends these observations to injection drug users with HIV infection as previous 
reports have either exclusively (8-10) or predominantly (11) focused on gay or bisexual men. Diffuse morphological change (increased atrophy) accompanied neurologic deterioration, but was not seen in neurologically asymptomatic HIV+ subjects with any greater frequency than in HIV subjects. Decline in CD4 count (a marker of disease progression in HIV infection) was associated with increased central atrophy. While there is evidence for early invasion of the central nervous system in HIV infection (12), the paucity of clinical and MRI changes in these follow-up study subjects (admittedly a group of survivors) suggests that the impact of this invasion is delayed, is seen only in a minority of subjects over a one year period and may not be evident until advanced disease ensues.

\section{REFERENCES}

1. Gorman J, Kertzner R, Todak G, Goetz R, Williams J, Rabkin J et al. Multidisciplinary baseline assessment of gay men with and without HIV infection, I: overview of study design. Arch Gen Psychiatry. 1991; 48: 120-3.

2. Stern Y, Marder K, Bell K, Chen J, Dooneief G, Goldstein S et al. Multidisciplinary. baseline assessment of gay men with and without HIV infection: III. Neurological and Neuropsychological findings. Arch Gen Psych 1991; 48: 131-8.

3. Nomenclature and research case definitions for neurologic manifestations of human immunodeficiency virus-type 1 (HIV-1) infection. Neurology 1991; 41 : 778-85.

4. Fleiss J. Statistical Methods for Rates and Proportions. New York, NY: John Wiley \& Sons Inc; 1981.

5. SAS User's Guide: Statistics. 5 ed. Cary, NC: SAS Institute; 1988.

6. Kurtzke J. Rating neurologic impairment in multiple sclerosis: an expanded disability status scale (EDSS). Neurology 1983; 33: 1444-1452.

7. Dooneief G, Bello J, Todak G, Mun I-K, Marder K, Malouf R et al. A prospective controlled study of magnetic resonance imaging of the brain in gay men and parenteral drug users with human immunodeficiency virus infection. Arch Neurol 1992; 49: 38-43.

8. McArthur JH, Nance-Sproson TE, Dal Pan GJ, Aylward E, Selnes O, Matthews $\mathrm{V}$ et al. A longitudinal study of brain magnetic resonance imaging (MRI) findings in HIV-1 infected homosexual men: the multicenter AIDS cohort study (MACS) [abstract]. Proceedings of Neuroscience of HIV infection-basic and clinical frontiers update; Padua, Italy 1991; p. 131.

9. Dal Pan GJ, McArthur JH, Aylward E, Selnes O, Nance-Sproson T, Kumar A et al. Patterns of cerebral atrophy in HIV-1-infected individuals. Neurology 1992; 42: 2125-30.

10. Manji H, Connolly S, McAllister R, Valentine A, Kendall B, Fell M et al. Serial MRI of the brain in asymptomatic patients with HIV infection: results from the UCMSM/Medical Research Council neurology cohort. J Neurol Neurosurg Psych 1994; 57: 144-9. 
11. Post MJD, Berger JR, Duncan R, Quencer RM, Pall L, Winfield D. Asymptomatic and neurologically symptomatic HIV-seropositive subjects: results of long-term MR imaging and clinical follow-up. Radiology 1993; 188: 727-33.

12. Grant I, Atkinson JH, Hesselink JR, Kennedy C, Richman D, Spector S et al. Evidence for early central nervous system involvement in the acquired immunodeficiency syndrome and other human immunodeficiency infections. Ann Int Med 1987; 107: 828-36.

for faculty/professionals with journal subscription recommendation authority for their institutional library...

If you have read a reprint or photocopy of this article, would you like to make sure that your library also subscribes to this journal? If you have the authority to recommend subscriptions to your library, we will send you a free sample

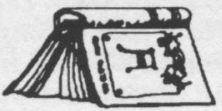
copy for review with your librarian. Just fill out the form below-and make sure that you type or write out clearly both the name of the journal and your own name and address.

( ) Yes, please send me a complimentary sample copy of this journal:

(please write in complete journal title here-do not leave blank)

I will show this journal to our institutional or agency library for a possible subscription.

The name of my institutional/agency library is:

NAME:

INSTITUTION:

ADDRESS:

CITY:

STATE:

ZIP:

Return to: Sample Copy Department, The Haworth Press, Inc., 10 Alice Street, Binghamton, NY 13904-1580 